\title{
Evaluation of MM5 Optically Thin Clouds over Europe in Fall Using ICESat Lidar Spaceborne Observations
}

\author{
H. Chepfer, M. Chiriaco, And R. VAutard \\ LMD/IPSL, Université Pierre et Marie Curie, Paris, France
}

J. SPINHIRNE

NASA GSFC, Greenbelt, Maryland

(Manuscript received 6 February 2006, in final form 6 October 2006)

\begin{abstract}
The description of clouds in mesoscale models has progressed significantly during recent years by improving microphysical schemes with more physical parameterizations deduced from observations. Recently, the first lidar in space, the Ice, Cloud, and Land Elevation Satellite (ICESat)/Geosciences Laser Altimeter System, has collected a valuable dataset that improves the knowledge of occurrence and macrophysical properties of clouds, and particularly high-altitude clouds, which are usually optically thin. This study evaluates the capability of the fifth-generation Pennsylvania State University-NCAR Mesoscale Model (MM5) to reproduce optically thin clouds using the ICESat October-November 2003 dataset. Initial and boundary conditions are prescribed from NCEP products and MM5 run over the European continent with a 40-km spatial resolution. Spaceborne lidar profiles are diagnosed from model outputs and compared with the observed ones at the same location and time. One month of simulations-observations comparisons shows that the model correctly reproduces cloud structures on average, but underestimates the thinnest clouds (by $0 \%-20 \%$ ) and overestimates less thin clouds in the upper troposphere (altitude $>6 \mathrm{~km}$ ). The total low-level water cloud amount (altitude $<6 \mathrm{~km}$ ) appears fairly well reproduced, although the masking effect of higher clouds does not allow for a firm conclusion. The clouds are rarely simulated and observed simultaneously, $50 \%$ for high clouds and $20 \%$ for low clouds. The lack of high-altitude very thin clouds is possibly due to dry biases in the upper-troposphere humidity fields used to force the model. The overestimation of optically less thin cloud may be due to an overestimation of the cloud lifetime or water vapor supersaturation around ice clouds that is not taken into account in the model. When the upper troposphere and low warm clouds appear in the model at the same time and location as in the observations, they are optically too thick, likely because their water/ice content and particle concentration are overestimated simultaneously.
\end{abstract}

\section{Introduction}

Clouds play a major role on the climate through their effects on the earth-atmosphere radiative balance and the water cycle. Among others, strong uncertainties remain on the physics and radiative properties of the cold high-altitude clouds (Liou 1986, 2002; Stephens et al. 1990). These latter cover a wide area of the earth's surface and their net radiative effect is largely uncertain. The balance between heating and cooling effects at the global and local scale depends on their macro-

Corresponding author address: Helene Chepfer, LMD/IPSL, Université Pierre et Marie Curie, 4, Place Jussieu, Paris, France. E-mail: chepfer@lmd.polytechnique.fr and microphysical properties. Despite strong efforts involving both observations and models in the last twenty years to improve our knowledge of high clouds, they are still roughly described in regional or global climate models. Furthermore, their climatological, total amount, and spatiotemporal variability are still too poorly known and local properties are still not accurately described from observations. These problems lead to very large uncertainties in their impact on climate sensitivity (Yakohata et al. 2005).

These knowledge gaps are largely connected to the difficulty in obtaining accurate observations of high clouds at their standard altitude $(6-14 \mathrm{~km})$, especially in the case of semitransparent clouds. Cirrus clouds have been observed routinely from ground-based re-

DOI: $10.1175 /$ MWR3413.1

(C) 2007 American Meteorological Society 
mote sensing (Ackerman and Stokes 2003; Haeffelin et al. 2005; Sassen and Benson 2001; Campbell et al. 2002) and with airborne in situ measurements during intensive field experiments in the midlatitudes (Randall et al. 1996; Raschke et al. 1998; McFarquhar and Heymsfield 1996; Toon and Miake-Lye 1998) and also more recently in the Tropics (McFarquhar and Heymsfield 1996; Jenson et al. 2004). The satellite remote sensing community has developed techniques to derive the climatology (Rossow and Schiffer 1999; Jin et al. 1996; Wylie et al. 1995; Wylie and Wang 1999; Minnis et al. 1998; Platnick et al. 2003; King et al. 2003; Baum et al. 2000; Goloub et al. 2000; Chepfer et al. 2001; etc.) of high clouds macrophysical and microphysical properties using the capabilities of the most recent satellite imagery such as the International Satellite Cloud Climatology Project (Rossow and Schiffer 1999), Moderate Resolution Imaging Spectroradiometer (King et al. 1996), and Polarization Directionality and Earth Reflectances (Deschamps et al. 1994). Those studies use passive remote sensing observations that present the advantage of having good spatiotemporal coverage, but these observations are not resolved vertically and hardly detect very thin cloud layers.

Lidars provide powerful means of observing high clouds, especially optically thin clouds, which are difficult to detect from passive remote sensing (Platt 1973; Sassen 1991; Bissonnette et al. 2001; Noel et al. 2006; Hart et al. 2005). Despite the difficulties generated by low-cloud masks, ground-based lidar studies of these clouds have allowed researchers to gain limited insight into their spatial and seasonal distribution, cloud amounts, optical depths, particle size, and relationships between particle size and temperature (Heymsfield and Platt 1984), thermodynamical phase and temperature (Sassen and Benson 2001), and particle shape and temperature (Noel et al. 2006).

In 2003, spaceborne lidar observations were collected during the Ice, Cloud, and Land Elevation Satellite (ICESat) mission. These top-down lidar profiles bear unprecedented promises for the study of high-altitude clouds as the beam scatters little before reaching the cloud. This property is particularly interesting for the establishment of high-cloud climatologies as they are always "seen," unlike when using the ground-based lidars where attenuation by lower-level water clouds results in nondetection of higher cloud layers. In the future such lidars, like the Cloud-Aerosol Lidar and Infrared Pathfinder Satellite Observation or Earth-Care missions will enable more cloud observations.

Along with the increase in our knowledge of high clouds, accurate remote sensing observations will allow the evaluation of global or regional climate models' ability to predict high-cloud occurrence frequency, spatial distributions, and radiative properties. This analysis is key in producing a more accurate understanding of present climate prediction of climate change under anthropogenic pressure. These models include specific microphysics schemes to describe ice clouds. These schemes have to take into account high-cloud properties by including advanced parameterizations to describe the different processes such as the growth of ice crystals, evaporation/saturation of water amount, changes in thermodynamical phase (solid-liquid water phase conversion), and fall of the particles. Moreover, the specific optical properties of optically thin clouds have to be considered in the models' radiative schemes. New parameterizations deduced from observations are progressively incorporated within the microphysical ice scheme (i.e., Dudhia 1989, 1993; Reisner et al. 1998; Heckman and Cotton 1993; Levkov et al. 1992, 1998; Boucher et al. 1995; Del Genio et al. 1996) in meso- and large-scale models. The physical properties of ice clouds also play a greater role in model radiative schemes through more realistic optical properties [single scattering albedo, extinction coefficient (Takano and Liou 1989; Macke et al. 1996; Yang and Liou 1998)] deduced from observations. As progress increases in both observations and models, more direct comparisons between them become possible.

Several recent studies (Guichard et al. 2003; Palm et al. 2005; Chiriaco et al. 2006) have used remote sensing observations to evaluate mesoscale capability to reproduce high- and low-level clouds. Here we used the spaceborne lidar ICESat dataset collected above Europe in order to evaluate the ability of the fifth-generation (version 3.6) Penn State University-National Center for Atmospheric Research mesoscale model (MM5) to reproduce optically thin high clouds in midlatitudes. We used a simplified but robust model-to-satellite approach that consists of diagnosing the lidar level-1 data observations (normalized and calibrated signal) directly from model outputs. The simulated lidar signal predicted from the model is therefore compared with its observed counterpart. The advantage of this model-toobservation approach lies in the absence of any inversion of the observed lidar signal, reducing the sources of possible errors to be the cause of discrepancy between observations and model.

The model formulation described in section 2. Section 3 follows with a description of the ICESat dataset. The model-to-observation method used to compare simulated with observed clouds is detailed in section 4 and illustrated with a case study. A statistical study is then carried out over one full month of observations, 
and its results are presented in section 5. The first stage of the analysis focuses on the cloud occurrence discrepancy between observations and model (section $5 b$ ), and the second stage aims to explain differences in the cloud properties (section 5c) simulated and observed using the subdataset of instances where clouds occur simultaneously (time and location) in both the observation and model. A discussion and conclusion are given in sections 6 and 7, respectively.

\section{Model configuration}

The MM5 (Dudhia 1993) is used in this study. The domain used covers most of western Europe with a horizontal resolution of $36 \mathrm{~km}$. The surface is initialized at the beginning of the simulation using the National Centers for Environmental Prediction (NCEP) soil temperature/soil moisture analyses coming from the Noah land surface model (LSM). In MM5 the same model is used (LSM) in order to calculate timedependent soil moisture and temperature, and fluxes of heat and water. The time evolution step is that of the dynamical model. The atmosphere is discretized into 61 vertical layers from the surface to $100 \mathrm{hPa}$, with sigma levels decreasing by 0.02 in the upper layers, leading to a vertical resolution of approximately $500 \mathrm{~m}$ in uppertroposphere ice clouds and $100 \mathrm{~m}$ in the boundary layer. Simulations are $30 \mathrm{~h}$ long, each simulated day being initialized at 1800 UTC on the day before with NCEP humidity, temperature, and wind analyses at $1^{\circ}$ horizontal resolution. The operational NCEP model, Global Forecast System (GFS), is used here, where relative humidity is assimilated from radiosondes up to $300 \mathrm{hPa}$ and from Geostationary Operational Environmental Satellite (GOES) radiances from 300 to 100 $\mathrm{hPa}$. To avoid divergence from the analysis, a nudging procedure is applied on wind and temperature fields with a 6-h relaxation time. The humidity field is not used in the nudging procedure in order to avoid the forcing of water variables and to leave the microphysics scheme unperturbed. Nevertheless, in the course of the model run, the nudged temperature does influence the microphysics. Because our aim is to evaluate the microphysical scheme and not its input parameters like temperature, temperature nudging helps to remove one source of error if observed and simulated clouds differ.

The Grell (1993) scheme is used for convection. The boundary layer parameterization from Troën and Mahrt (1986) is selected, with a modified formulation of the convective velocity (Beljaars 1995) as suggested by Liu et al. (2004). The radiation scheme is from Hack et al. (1993) with a modification of the ice particle di- ameter taken equal to $35 \mu \mathrm{m}$ instead of $14.6 \mu \mathrm{m}$ (Chiriaco et al. 2006). Reisner et al. (1998) is used for the microphysical scheme with a modified parameterization of the ice particle sedimentation velocity (Heymsfield and Donner 1990) depending on the ice mixing ratio as suggested in Chiriaco et al. (2006). The mass contents for liquid water, rain, graupel, snow, and ice are prognostic variables together with the ice particle number. The size distributions are derived from the mass contents and the particle concentration. For liquid particles, the particle concentration is assumed constant as given in the model.

Previous studies have allowed highlighting some limitations of MM5 in producing clouds. Based on groundbased observations, Chiriaco et al. (2006) have shown that (i) MM5 model misses very thin clouds; and (ii) high $(z>8.5 \mathrm{~km})$ and low $(z<6 \mathrm{~km})$ cloud occurrences are underestimated, whereas middle $(7 \mathrm{~km}<z<8.5$ $\mathrm{km})$ clouds are overestimated. Reisner et al. (1998) have shown that (i) riming and depositional growth is too high; (ii) large-scale characteristics must be correctly simulated in order to get good results for the microphysical scheme; and (iii) one key point for the cloud representation is the vertical resolution of the model in inversion areas (ideal should be adaptive grids). Wetzel and Bates (1995) have pointed out that (i) there is a negative bias of $10 \%-30 \%$ between model and observations (GOES) concerning the cloud fraction, in July; and (ii) that correlations between model and observations (GOES) are better in mountain areas in summer.

\section{ICESat data}

The ICESat launched as a low orbiting satellite carrying a lidar onboard a satellite platform. The instrument is called the Geosciences Laser Altimeter System (GLAS) and is an NdYag lidar emitting at 532 and 1064 $\mathrm{nm}$ with a pulse repetition frequency of $40 \mathrm{~Hz}$, a nominal optical power of $40 \mathrm{~mJ}$ (4 Watts) and a divergence of $0.1 \mathrm{mrad}$. The footprint is about $75 \mathrm{~m}$ at the tropopause level in midaltitudes. The ICESat mission has collected 4-6 weeks of data every 3-4 months since the launch and is continuing to collect data.

The current study uses the 532-nm backscattered attenuated profiles, which are calibrated and normalized against theoretical molecular profiles computed from NCEP thermodynamical profiles (GLA07 product). This study used more than 45 days of observations collected between 14 October and 15 November 2003. The satellite passed over Europe 2 to 3 times a day around 0700 and 1900 UTC and only segments of orbits cross- 
TABLE 1. Observed and simulated datasets.

\begin{tabular}{|c|c|c|}
\hline \multicolumn{2}{|r|}{ Observations } & \multirow[t]{2}{*}{ Used in } \\
\hline Data_obs_0 & All the observations points (including saturated points) & \\
\hline Data_obs_1 & All the nonsaturated points observed & Section $5 \mathrm{a}$ \\
\hline Data_obs_2 & $\begin{array}{l}\text { All the nonsaturated points observed that are contained in a cloudy profile (cloud } \\
\text { detection applied to observed profiles) }\end{array}$ & Section $5 b$ \\
\hline Data_obs_3 & $\begin{array}{l}\text { All the nonsaturated points observed that are contained in a cloudy profile when both } \\
\text { observations and simulations consistently detect a cloud at the same time and location }\end{array}$ & Section $5 \mathrm{c}$ \\
\hline \multicolumn{2}{|r|}{ Simulations } & Used in \\
\hline Data_sim_0 & All the simulated points & Section 4 \\
\hline Data_sim_1 & All the simulated points & Section 5 \\
\hline Data_sim_1bis & All the simulated points associated to nonsaturated points observed & \\
\hline Data_sim_2 & $\begin{array}{l}\text { All the simulated points that are contained in a cloudy profile (cloud } \\
\text { detection applied to simulated profiles) }\end{array}$ & Section $5 b$ \\
\hline Data_sim_3 & $\begin{array}{l}\text { All the simulated points, that are contained in a cloudy profile when both } \\
\text { observations and simulations consistently detect a cloud at the same time and location }\end{array}$ & Section $5 \mathrm{c}$ \\
\hline
\end{tabular}

ing Europe are considered here. One crossing of Europe typically takes $6 \mathrm{~min}$, so that the measurements used here can be considered as a quasi-instantaneous picture of the state of the atmosphere.

The nominal GLAS laser emission is $40 \mathrm{~Hz}$, here the $5-\mathrm{Hz}$-averaged profiles have been used and reaveraged over $0.5^{\circ} \times 0.5^{\circ}$ latitude-longitude boxes for consistency with the model spatial resolution. Thus each measured profile to be compared with the model is typically averaged over $8 \mathrm{~s}$ and one cross section of the European continent is described by approximately 40 profiles depending on the orbit considered. So, the signal is averaged over a line approximately $55 \mathrm{~km}$ long and $66 \mathrm{~m}$ wide. In broken cloud conditions, ICESat may not encounter any clouds even if they are present on the side of the fly track in the same grid box, increasing the likelihood of nondetection. On one hand, this satellite observation limitation may be significant for low-level cumulus convective clouds (even if autumn is not the more convective season). On the other hand, those small-scale clouds are also a challenging subgrid-scale phenomena from the model point of view. The averaging allows the data to be equalized to the model spatial resolution, but also improves the signal-to-noise ratio of the measured profiles. The vertical resolution of the measured lidar profiles is $76.8 \mathrm{~m}$. Only the points closest to the model altitude levels are kept for modelobservation comparisons. The 14 October-15 November dataset is composed of 77 orbits in total spread over the European continent.

\section{Method}

To compare lidar observations with model prediction, we compute theoretical lidar profiles that would be observed if the atmosphere had the composition predicted by the model. The theoretical lidar profile is simulated from MM5 outputs using the active remote sensing simulator (ActSim) code described in Chiriaco et al. (2006). This code simply consists of computing a theoretical lidar profile using the lidar equation including the attenuation (see the appendix). The following outputs of MM5 are inputs of ActSim: ice, snow, liquid water contents, and associated particle concentrations at each level of atmosphere. The particle optical properties at $532 \mathrm{~nm}$ are computed with Mie theory because MM5 implicitly assumes atmospheric particles to be spherical. The shape of the size distributions are prescribed as in the Reisner et al. (1998) cloud microphysical scheme to keep consistency with the model. The multiple scattering effects are taken into account by applying Platt (1978) empirical corrections (multiple scattering coefficient $\eta=0.5$ ). NCEP thermodynamical profiles (pressure and temperature) are used to compute the molecular contribution to the lidar profile. Both measured and simulated profiles are normalized to the molecular signal above the tropopause, so they can be compared directly. The model outputs are computed at each hour, whereas the satellite overpass time is variable. The comparison between observed and measured profile uses the model output closest to the observation. The time difference between both can reach a maximum of $30 \mathrm{~min}$. The entire simulated dataset is called Data_sim_0 (Table 1).

Figure 1 shows an example of observed lidar profiles as a function of latitude and the corresponding simulated profiles for the 1850 UTC 23 October European cross section. For this case, the main cloud structures are reproduced by the model even though some of the lower clouds (below $4 \mathrm{~km}$ ) are missed by the model. 


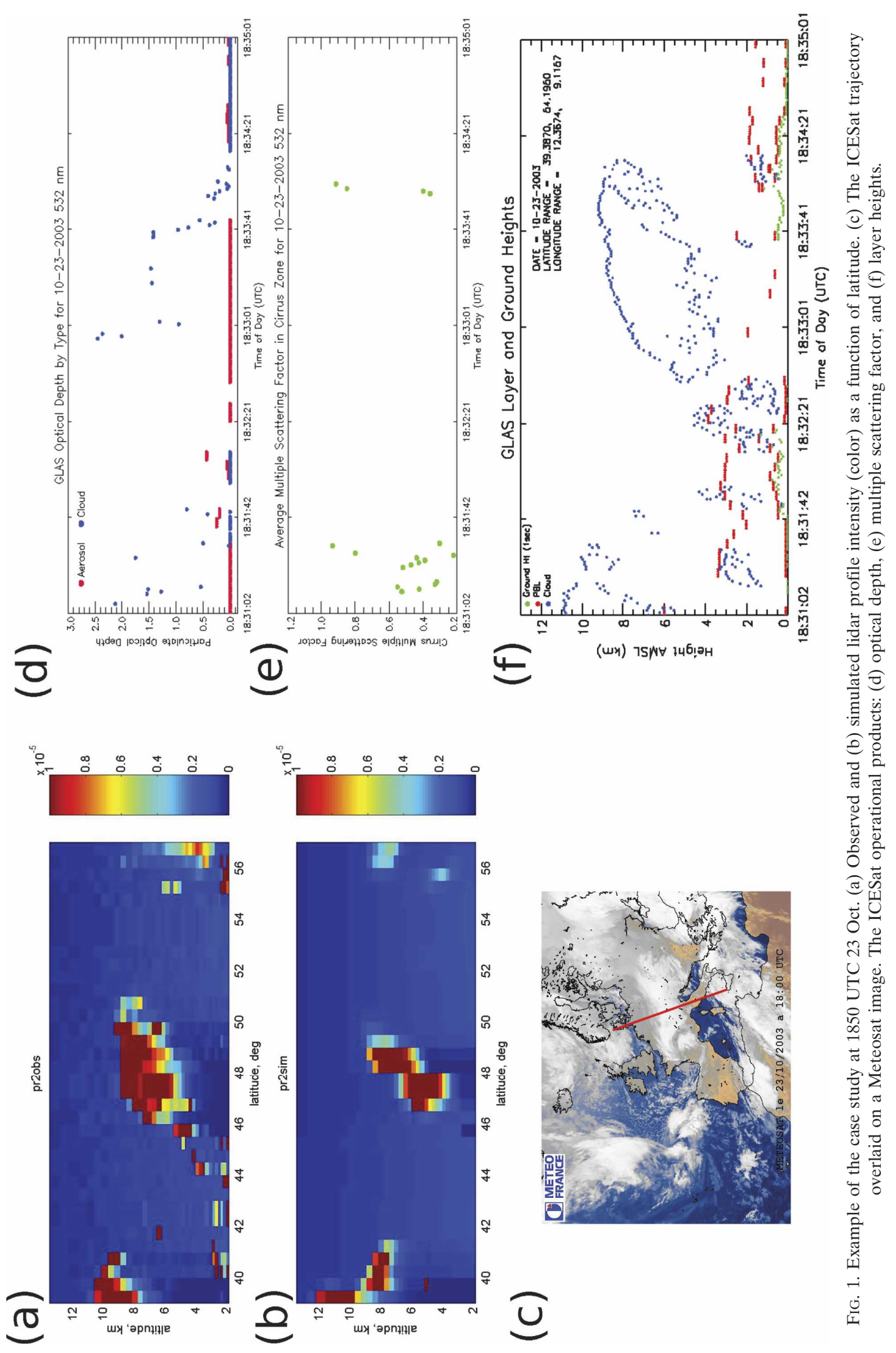


The corresponding satellite ground track is shown in Fig. 1c indicating that it crosses a well-formed frontal system. Complementary analyzes of case-by-case comparison (not shown) confirm that the model captures most of the cloud structure when the satellite crosses the bulk of a frontal system, the strongest discrepancy between simulated and observed signals occurs when the satellite track is located at the edge of the cloud structures.

For confirmation, the GLAS operational data products (Spinhirne et al. 2005) are shown in Figs. 1d-f. The operational-derived cloud-height levels indicate the presence of clouds as shown previously but also some aerosol layers are found episodically in the boundary layer. Aerosol particles are not taken into account in the lidar simulated profiles. Also shown in Fig. 1 are calculations of cloud optical thickness of layers and the lidar multiple scattering factor, described later, as effective for the signal at the ground. These parameters are only calculated where the cloud is sufficiently optically thin (typically, optical depth lower than 2.5) and without saturation over a one-second average (Hlavka et al. 2005). Most of the clouds shown are beyond the optical thickness limit. The maximum cloud optical depth retrieved from observation is 2.5 , and the multiple scattering factor is between 0.2 and 1 .

In the statistical study presented hereafter, an observed lidar signal and its simulated counterpart are used only if the measured lidar signal is not saturated. When saturation occurs in an observed profile, the nonsaturated points above are kept for analysis. This means that the top of thick clouds up to the limit of attenuation is kept in the dataset. Those datasets (without the saturated points) are called Data_obs_1 and Data_sim1 (Table 1). They are built from Data_obs_0 and Data_sim0, using the saturation/nonsaturation of the lidar profile flagged at each level of altitude in the GLAS measurements (called i5_g_sat in the Gla07 data product). This flag indicates whether the corresponding bin in the $5-\mathrm{Hz} 532-\mathrm{nm}$ profile is saturated or not. The saturated condition occurs when the received photon count for a bin is greater than nine counts per detector for each of the four detectors for a given shot. Usually, the saturation condition occurs only for relatively lowlevel, liquid-water clouds. Most of the observations located above $6 \mathrm{~km}$ are not saturated (95\%) nearly independently of the altitude $(6<z<13 \mathrm{~km})$, so that the high level clouds dataset used here is significant and not limited to the ice cloud top layer. Thus the analysis of the difference between simulations (Data_sim_1) and observations (Data_obs_1) is not hindered by the lidar penetration problem.

\section{Results of statistical comparison}

This section aims at comparing the mean simulated and observed lidar signals (section 5a), the cloud occurrences observed and simulated (section 5b), and the differences between cloud properties observed and simulated in the subdataset where clouds occur consistently in observations and simulations (section 5c)

\section{a. Comparison of mean simulated and observed signals}

The mean lidar signals over the complete dataset (Data_obs_1 and Data_sim_1) are plotted in Fig. 2a together with the number of points averaged at each level of altitude (Fig. 2b). Similar plots for the subdataset corresponding to time differences between model and observations of 15 and $5 \mathrm{~min}$, respectively (not shown), give similar results whatever the restriction on the time differences. The simulated lidar signal is consistent with the observed one above $11.5 \mathrm{~km}$, it is overestimated between 7 and $11.5 \mathrm{~km}$, and underestimated below $7 \mathrm{~km}$.

The interpretation of the differences between simulated and observed lidar profiles are not straightforward in terms of cloud differences, as an overestimation of simulated high-cloud backscattering inherently leads to an underestimation of the signal below. Thus the nearing of the mean simulated profile to the molecular baseline between 3 and $5 \mathrm{~km}$ does not mean that the model never simulates clouds at this altitude. Large low-level underestimations may also suffer from higher levels backscattering overestimation. The only firm conclusion that can be drawn from Fig. $2 \mathrm{a}$ is that model high optically thin clouds have a backscattering power higher than in the observation.

To investigate the disagreement between observed (black) and simulated (red) signals (Fig. 2), the lidar signal has been simulated by considering independently the different particle categories produced by the model: liquid water, snow, and ice without the other phases. As the model parameterization imposes changes of the thermodynamical phase as a function of temperature thresholds, the main contribution of ice is logically obtained in the upper clouds layers and the liquid water in the lower clouds. Above $6.5 \mathrm{~km}$, associated with temperatures around $-30^{\circ} \mathrm{C}\left( \pm 15^{\circ} \mathrm{C}\right)$, the contribution of liquid water is negligible and the contribution of snow is very small, hence most of the discrepancy obtained between model and observations between the tropopause and $6.5 \mathrm{~km}$ is due to the ice scheme in MM5, multiple scattering effects hypothesis in ActSim, and/or errors in the thermodynamical fields used to force the model at high altitudes. 
(a)

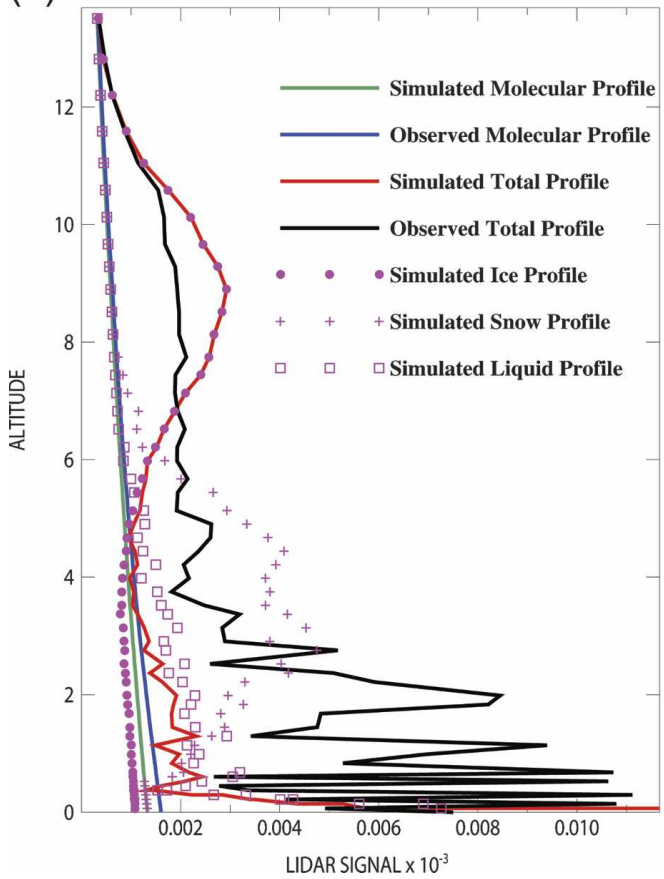

(b)

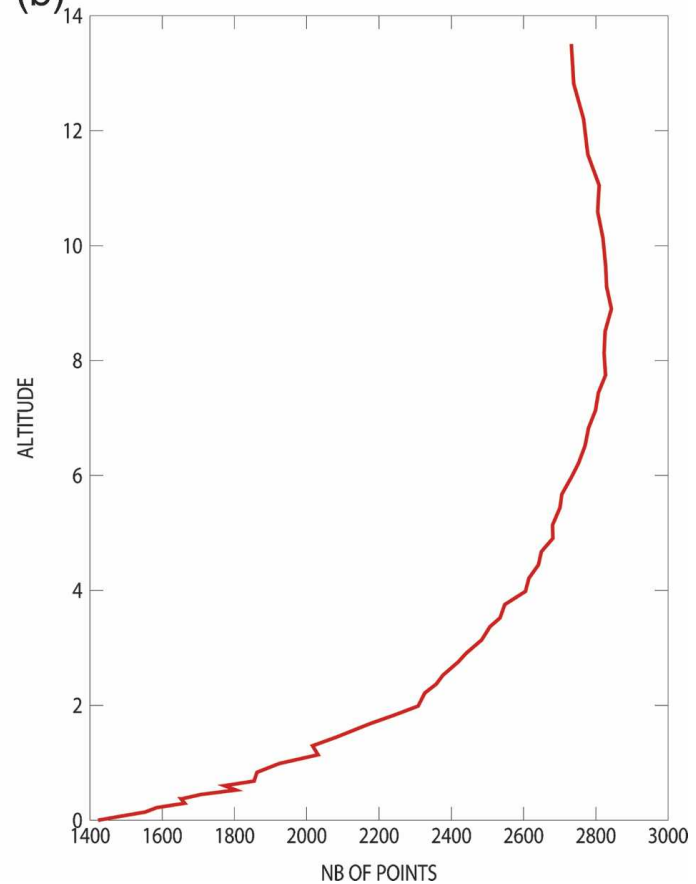

FIG. 2. (a) Mean observed (Data_obs_1) and simulated (Data_sim_1) lidar profiles (Data_obs_1) over the 77 orbits. (b) Number of points averaged to compute the mean profiles.

The backscattering profile produced by snow alone is significant between 3 and $6 \mathrm{~km}$, and it is much higher than that of the total signal. Thus in the total signal the presence or absence of snow cannot explain by itself the model underestimation, which results in large part from the optically too thick ice clouds. At lower altitudes $(0-3 \mathrm{~km})$ the total signal is also probably largely affected by the ice clouds masking effect. However the mean water profile has smaller amplitude than that of the snow profile. A small amount of optically thin liquid water clouds is produced by the model, but a large fraction of the liquid water clouds are optically thicker than 2.5 and precluded of the dataset because of the lidar limitation penetration.

\section{b. Cloud occurrence}

\section{1) Number of CLOUd EVENTS}

Differences between observations (Data_obs_1) and simulations (Data_sim_1) can be due to errors in the cloud occurrence and/or in the cloud properties [i.e., ice water content (IWC), liquid water content (LWC), snow water content, particle concentration, etc.] predicted by the model. To distinguish between these two possible causes, the same rough cloud detection is applied independently to the observed and simulated lidar signals. The cloud data resulting from this cloud detec- tion are called Data_obs_2 and Data_sim_2 (Table 1). The cloud detection consists of searching for differences between the cloud signal and the molecular signal larger than a threshold value. If such a difference is encountered, the atmosphere is considered as cloudy. Various threshold values $\left(0,10^{-7}, 10^{-6}, 10^{-5} \mathrm{~W} \mathrm{~m}^{2}\right.$ $\mathrm{sr}^{-1}$ ) have been tested for the cloud detection. The molecular signal is typically of the order of $3 \times 10^{-7}$ in the upper troposphere (Fig. 2), hence a threshold of $10^{-7}$ allows avoiding false detection, but may miss optically very thin cloud/aerosols layers. For the $10^{-7}$ threshold, $30 \%$ of the pixels contain in Data_obs_1 are identified as cloudy in the observations, $10 \%$ are located at altitudes higher than $6.5 \mathrm{~km}$ and $20 \%$ at lower levels. The other $70 \%$ of Data_obs_1 pixels correspond to cloudyfree areas. These numbers should not be interpreted as a cloud coverage because here a pixel corresponds to a level of altitude at a given location at a given time, the atmospheric column is composed of 61 different levels from the ground to $13 \mathrm{~km}$.

Comparisons between observations (Data_obs_2) and simulations (Data_sim_2) are summarized in Table 2. Here clouds are counted using either the different water phases separately like in Fig. 2 (second half of the Table 2), or all phases together (first half of the Table 2 ). Whatever the threshold, the number of low-level $(<6 \mathrm{~km})$ clouds pixels observed is significantly larger 
TABLE 2. Cloud occurrences in observations and simulations. The numbers of cloudy pixels are computed by applying the same cloud detection independently to the observations and simulations (Data_obs_2 and Data_sim_2). Four different values of the detection threshold are considered. Values in brackets give the number of cloudy pixel simulated (Data_sim_3) at the same location (altitude and latitude) as an observed cloudy pixel, divided by the total number of cloudy pixel observed (Data_obs_2).

\begin{tabular}{|c|c|c|c|c|c|}
\hline Line No. & Detection threshold & 0 & $10^{-7}$ & $10^{-6}$ & $10^{-5}$ \\
\hline \multicolumn{6}{|c|}{ No. of cloudy pixels detected in observations } \\
\hline 1 & $>6 \mathrm{~km}$ & 22902 & 14000 & 6766 & 1419 \\
\hline 2 & $<6 \mathrm{~km}$ & 30794 & 26878 & 17645 & 5877 \\
\hline 3 & Entire column & 53696 & 40878 & 24411 & 7296 \\
\hline \multicolumn{6}{|c|}{ No. of cloudy pixels detected in simulations considering all particles categories } \\
\hline 4 & $>6 \mathrm{~km}$ & 17145 & 12549 & 9247 & 2087 \\
\hline 5 & $<6 \mathrm{~km}$ & 5277 & 4097 & 3068 & 1402 \\
\hline 6 & Entire column & 22422 & 16646 & 12315 & 3489 \\
\hline \multicolumn{6}{|c|}{$\begin{array}{c}\text { Ratio between the number of cloudy pixels simulated (considering all particles categories) and the No. of } \\
\text { cloudy pixels observed }\end{array}$} \\
\hline 7 & $>6 \mathrm{~km}(\%)$ & 75 & 88 & 137 & 147 \\
\hline 8 & $<6 \mathrm{~km} \mathrm{( \% )}$ & 17 & 15 & 17 & 24 \\
\hline 9 & All (\%) & 42 & 41 & 50 & 48 \\
\hline \multicolumn{6}{|c|}{ No. of cloudy pixels detected in simulations considering water and ice separately } \\
\hline 10 & Ice only $>6 \mathrm{~km}$ & 18550 & 13720 & 9472 & 2142 \\
\hline 11 & Water only $<6 \mathrm{~km}$ & 32333 & 22308 & 17821 & 2762 \\
\hline & \multicolumn{5}{|c|}{$\begin{array}{l}\text { Ratio between the No. of cloudy pixels simulated (considering water and ice separately) and the No. of cloudy } \\
\text { pixels observed }\end{array}$} \\
\hline 12 & Ice only $(\%)>6 \mathrm{~km}$ & $81(39)$ & $98(36)$ & $140(41)$ & $151(12)$ \\
\hline 13 & Water only $(\%)<6 \mathrm{~km}$ & $105(17)$ & $83(10)$ & $101(5)$ & $47(1)$ \\
\hline
\end{tabular}

than the higher clouds ( $>6 \mathrm{~km}$; see lines $1-3$ of Table 2 ) mostly because the vertical resolution is much finer at lower levels than at higher levels.

The simulated high cloud amount is lower than the measured one (line 7 of Table 2) for the small threshold values where the model misses about $12 \%$ of the optically thinner ice clouds in the upper troposphere (threshold $10^{-7}$ ). For large thresholds, the simulated high-cloud amount is greater than what is observed, meaning that the model produces too many optical thick clouds. Those features concerning high clouds are roughly confirmed when considering ice only in the simulations (lines 10 and 12 of Table 2).

The low water cloud amount is relatively well reproduced by the model when considering water alone below $6 \mathrm{~km}$ in the simulations (line 13 of Table 2). However these relatively good scores obtained when considering independently the two main cloud layers $(>6$ $\mathrm{km}$ and $<6 \mathrm{~km}$ ) are strongly degraded if we consider all the thermodynamical phases in the total atmospheric column (line 8). In this case more than half of the cloud observed are not detected in the simulation because of the presence of high clouds in the model. The low-level clouds (water) predicted by the model in a large amount are less frequently detectable (comparison between line 5 and 11). The difference is likely due to model errors in the description of upper-troposphere cloud properties that propagate to lower altitudes when considering the simulated lidar profile.

The initial ratios obtained independently for each phase above and below $6 \mathrm{~km}$, become too small if we consider correct (time and location) cloud hits (without any constraint on the lidar profile intensity, Data_sim_3 as defined in Table 1), as shown by the values in parentheses in Table 2 (lines 12-13). This degradation is larger for low-level water clouds, showing that cumulus and stratocumulus clouds are poorly predicted at the right location and time by the model. A visual inspection of lidar profiles confirmed that the poor pixel-topixel correlation is due to cloud misplacements.

Figure 3 shows the cloud occurrence as a function of latitude and altitude in the observations and simulations for a $10^{-7}$ threshold including the complete dataset. Both vary consistently with latitude, with two cloud layers occurring mostly in the boundary layer and in the upper half of the troposphere. Figures 3a,b confirm that most of the cloud amount below $6 \mathrm{~km}$, associated with temperatures of typically $0^{\circ} \mathrm{C}\left( \pm 15^{\circ} \mathrm{C}\right)$, are masked in the simulation by the presence of too frequent and too thick high clouds even though they are predicted by the model (Fig. 3c) but not necessarily predicted at the right time and location. Table 2 (line 5 
(a)
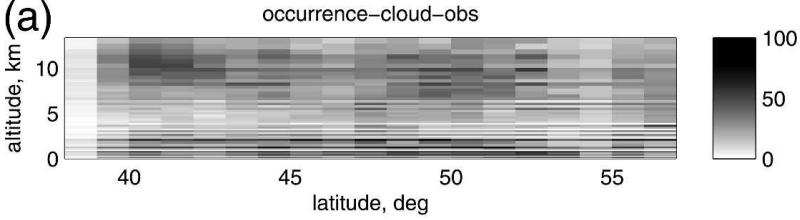

(b) occurrence-cloud-sim-all

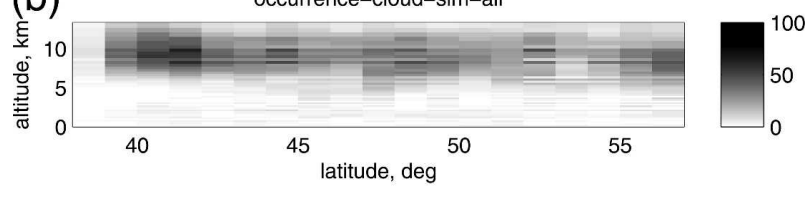

(C) occurrence-cloud-sim-water

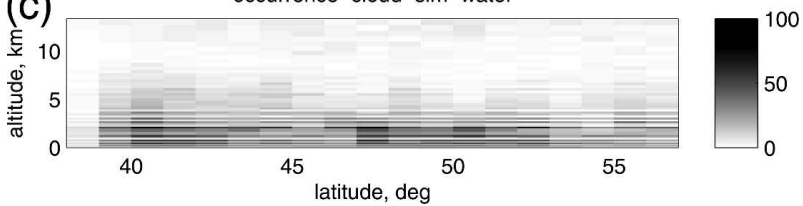

FIG. 3. Cloud occurrences as a function of latitude including the 77 ICESat European orbits using a detection threshold of $10^{-7}$ in the (a) Data_obs_2 observations and (b) Data_sim_2 simulations including all phases. (c) Same as (b) including water particles only.

and 11 ) indicates that $81 \%$ of the low-level clouds effectively produced by the model are masked by the presence of high clouds in the simulations. Note that it is not possible, like with the model, to isolate the observed lidar signal due to liquid water cloud. It is probable that high clouds also remove a large number of low clouds in the observations. Thus in any case the number of low clouds is most probably underestimated.

\section{2) LINK WITH THERMODYNAMICAL CONDITIONS}

Figure 4 shows the difference between the simulated and observed cloud occurrences for a detection threshold of $10^{-7}$. (The value 0 corresponds to agreement between observations and simulations whatever the conditions: cloudy or clear sky). This difference is plotted as a function of NCEP temperature and humidity to highlight the thermodynamical conditions in which the model under- or overestimates the cloud amount. Figure $4 \mathrm{a}$ indicates that the total cloud amount, including all thermodynamical water phase (liquid water, snow, and ice), is underestimated (negative values) or overestimated (positive values) depending on the temperature and humidity ranges. The model underestimates cloud over a cold temperature range $\left(-50^{\circ}\right.$ to $\left.-60^{\circ} \mathrm{C}\right)$ for a humidity range RHi $(20 \%-140 \%)$ and at a positive temperature range $\left(0^{\circ}-20^{\circ} \mathrm{C}\right)$ for a humidity range RHw $(60 \%-100 \%)$. The cloud amount is overestimated by the model at cold temperatures $\left(20^{\circ}\right.$ to $\left.-60^{\circ} \mathrm{C}\right)$ when $\mathrm{RH}_{\mathrm{i}}$ is ranging between $130 \%$ and $160 \%$. Figure 4c shows the same diagram but uses the ice phase only in the simulated signal: only the ice particles numbers prognosticated by the model are used to simulated the lidar profile (liquid water, graupel, rain, snow contribution are not taken into account). Similarities between Figs. $4 \mathrm{~b}$ and $4 \mathrm{c}$ for cold clouds indicate that most of the cloud amount errors identified previously are induced by the ice phase description in the model or by errors in the NCEP temperature and humidity fields that are used as an input for the simulations. The deficit of cloud amount at low values of RHi $<100 \%$ associated with optically thin clouds (small values of lidar signals, not shown) may be associated with cloud cases where the humidity amount is underestimated in NCEP fields. The cloud amount overestimations at cold temperature occur for both optically thin and thick clouds, independently of the cloud temperature when $\mathrm{RH}_{\mathrm{i}}$ is higher than $120 \%$.

Figure $4 \mathrm{~d}$ shows the same diagram but considering only simulated water clouds. Figure $4 \mathrm{~d}$ compared with Fig. 4a confirms that the count of low-level clouds is closer to the observed one as obtained with the lidar total signal. Once again this latter comparison does not take into account the masking effect in the observation, and there is a good chance that the simulated low-level cloud amount is underestimated. The model underestimated cloud amounts (negative values in Fig. 4d) occurring in the model at cold temperature are due to the presence of ice clouds in the observations, and cannot be attributed to a model deficiency (that uses water only here). On the contrary, at warm temperatures $\left(0^{\circ}-\right.$ $20^{\circ} \mathrm{C}$ ) for RHw between $60 \%$ and $80 \%$, the model fails to produce enough low-level water clouds. This may be due to the lack of fractional clouds in MM5, as a liquidwater cloud is formed only when RHw reaches $100 \%$ in a grid cell, while in reality subgrid fluctuations allow cloud formation at lower mean RHw. Finally as RHw is higher than $80 \%$, the warm cloud amount is slightly overestimated (Fig. 4c) between $0^{\circ}$ and $-10^{\circ} \mathrm{C}$.

\section{c. Cloud properties}

For the cases where both model and observations consistently detect a cloud at the same time and location (Data_obs_3 and Data_sim_3 defined in Table 1), the average observed and simulated signals are plotted in Fig. 5a. As mentioned in Table 2 (values in bracket), less than half of the ice clouds observed and less than $10 \%$ of the total low water clouds observed are effectively seen at the right time and location in the simulations and their postprocessed backscattering profile. The mean observed and simulated profiles are quite similar, while the amplitude of the signal is relatively well captured. The model overestimates the intensity of the lidar signal at altitudes ranging between 
(a)
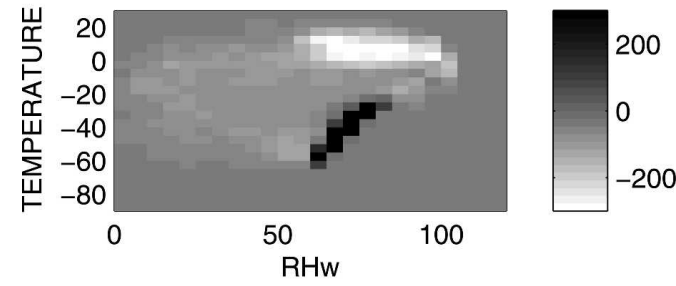

(c)

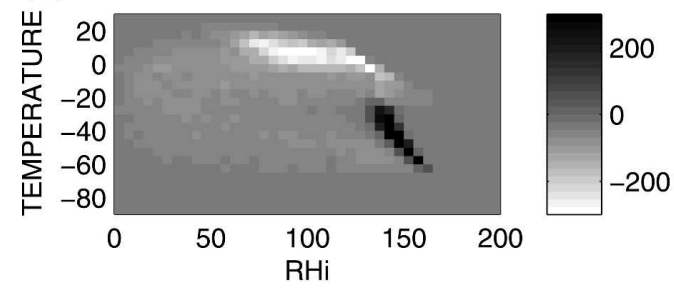

(e)

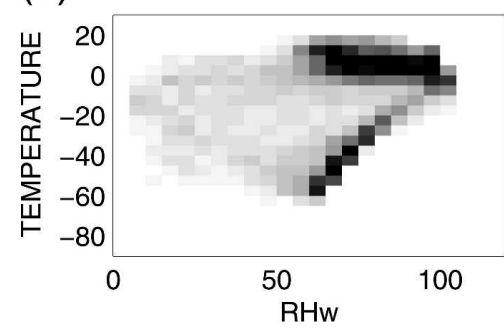

(b)

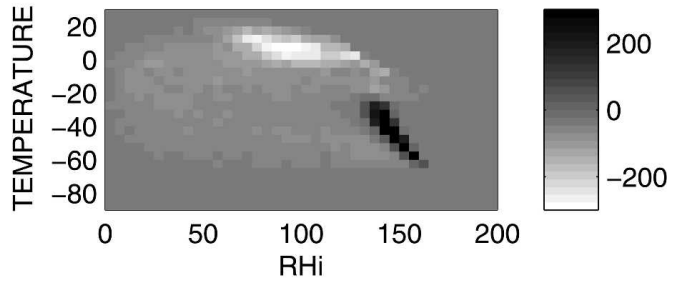

(d)

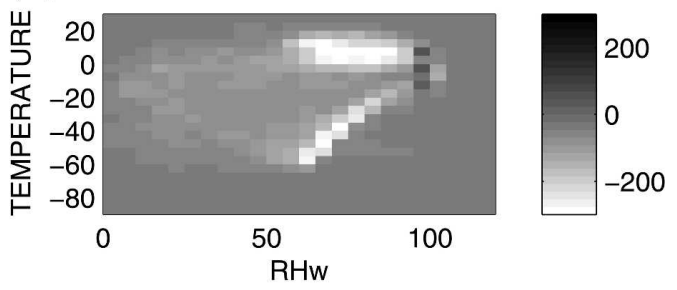

(f)

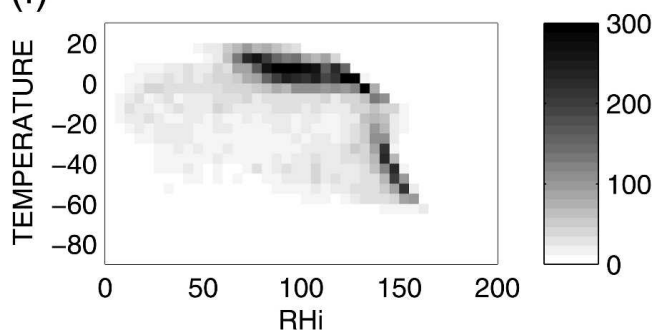

FIG. 4. Differences between the simulated and observed cloud occurrences as a function of temperature and humidity, (a) including all the thermodynamical phases in the simulated signal, as function of RHw. (b) Same as (a) but as a function of RHi, (c) including ice only in the simulated signal, as a function of RHi, (d) including water only in the simulated signal, as a function of RHw, (e) RHw, and (f) RHi.

7 and $10 \mathrm{~km}$ whatever the latitude, confirming that the ice cloud overestimation of Fig. 2a is not only due to a cloud occurrence deficiency but also to errors in the cloud physical and dynamical properties such as the ice content, particle size, and fall velocity.

The model underestimates the lidar signal between 4 and $6 \mathrm{~km}$ where the ice, liquid, and snow phases occur simultaneously (Fig. 2a). The model overestimates the lidar cloud signal below $2 \mathrm{~km}$, showing that when they occur in the model the low, warm model clouds are optically too thick, or the multiple scattering factor in ActSim is wrong. In this case the masking effect cannot account for the disparity.

Figure $5 \mathrm{~b}$ shows the mean atmospheric optical depth as estimated by the model using Data_sim_1 (triangles) as well as the mean optical depth when considering only cases where both observations and simulations simultaneously detect a cloud (solid) using Data_sim_3. In cloudy conditions (Data_sim_3), the mean optical depth is lower than 2 (Fig. 5b), on average, as estimated from the simulated signal, which is consistent with the limitation imposed by the lidar penetration. Above 6 $\mathrm{km}$, the mean optical depth of the clouds under study is 0.5 . Below $2 \mathrm{~km}$, the mean optical depth estimated by the model, including the complete nonsaturated dataset (Data_sim_1), is of the order of 7 when the corresponding observations only retain clouds with optical depth lower than 2.5 (lidar penetration, nonsaturated signal), confirming that when they appear in the model the lowlevel water clouds are significantly too thick optically.

The differences between the observed and simulated profiles are plotted as a function of pressure and temperature in Fig. 6. For the ice phase (Figs. 6a-c), the difference is nearly independent of the cloud temperature, but it is slightly more important at RHi around $150 \%$ (RHw around $80 \%$ ) than other humidity ranges. All the phases are represented in Figs. 6d-f. Differences between Figs. 6a-c and $6 \mathrm{~d}-\mathrm{f}$ are due to liquid water and snow. Figures $6 \mathrm{~d}$ and $6 \mathrm{e}$ show that for positive temperatures and $\mathrm{RHw}$ around $100 \%$, the simulated lidar signal produces by water cloud can be significantly larger than the one observed, indicating that 

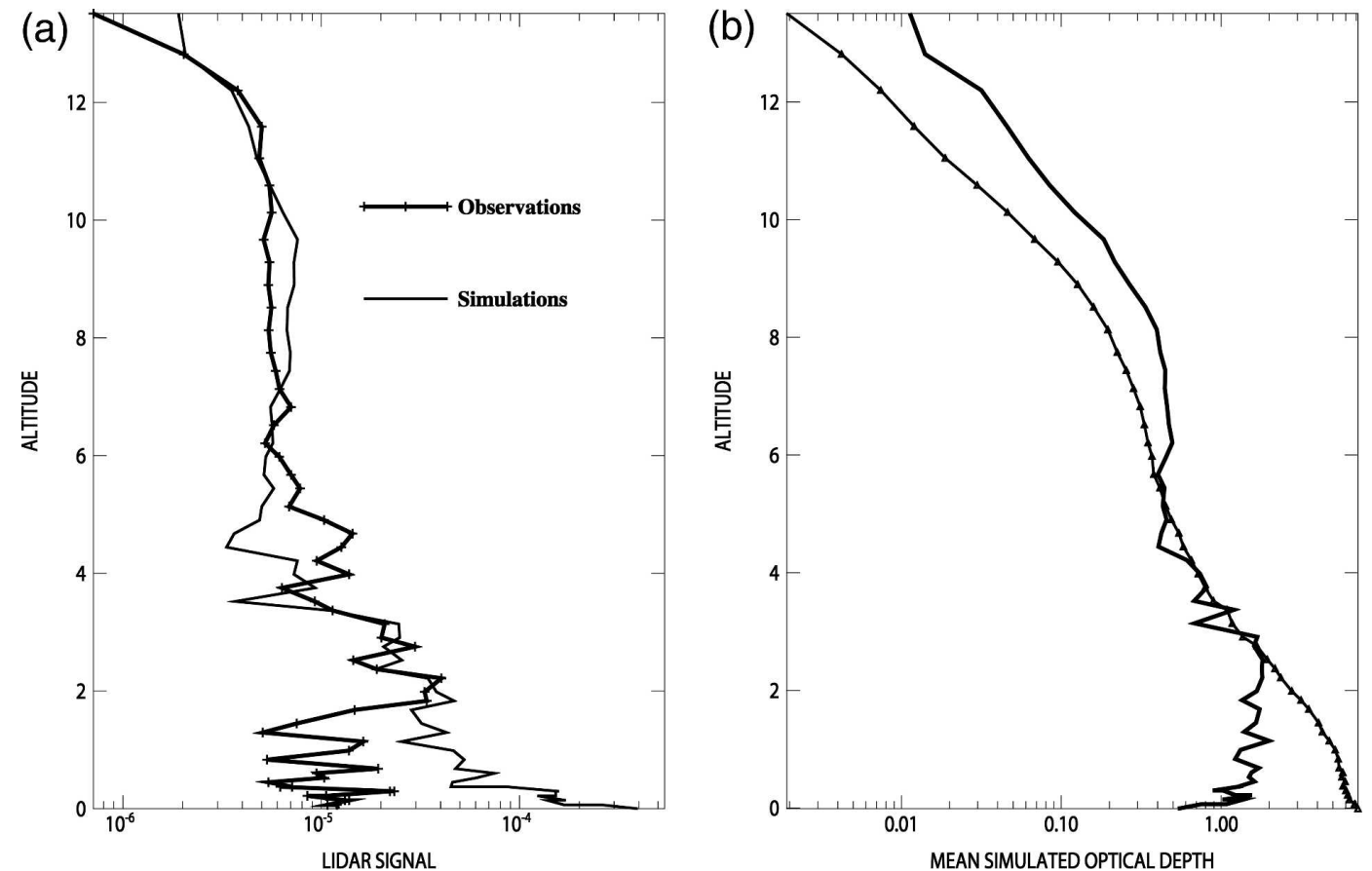

FIG. 5. (a) Mean observed and simulated lidar signal when clouds occurred simultaneously in observations and simulations (Data_obs_3 and Data_sim_3). (b) Mean simulated optical thickness from the $13 \mathrm{~km}$ to the altitude $z$ $[\tau(13 \mathrm{~km}, z)]$ when the observed signal is not saturated Data_sim_1bis (triangles) and when both simulation and observation consistently detect a cloud Data_sim_3 (solid line).

the water clouds simulated are optically too thick in those conditions when they appear in the model. Even if those phases (water/snow) appear less frequently than the ice phase in the simulated dataset, they are more biased, the simulated values being most of the time larger than the measured one as soon as RHw reaches $100 \%$, while there is no evident link with temperature.

\section{Discussion}

The previous results show that simulated and observed lidar signal profiles differ significantly when both observations and simulations detect a cloud. These differences can be caused by errors in the thermodynamical fields used to force the model, the cloud scheme within the model, and the hypothesis done in ActSim for simulating the lidar profile.

\section{a. The simulation of the lidar profile}

The simulation of the lidar profile (ActSim) uses a hypothesis to treat the multiple scattering effect of the laser beam during its path within the cloud. This phenomenon can take significant importance when the clouds are optically thick (Nicolas et al. 1997). The mul- tiple scattering phenomena is treated here by applying an empirical correction that consists of a factor of multiple scattering called $\eta$ introduced in the exponential of the transmission term of the lidar equation (see the appendix) as proposed by Platt (1978). For cloud particles larger than the lidar wavelength, which is the case here at least for ice and snow particles (Fig. 8), $\eta$ approximately takes the value of 0.5 because half of the energy interacting with the particle will be diffracted at very low angles, all this energy entering in the lidar telescope after possible multiple interactions with the particle (Platt 1978). For a lidar in space like ICESat the distance between the cloud and the telescope is large, and the large footprint allows photons at larger angles to stay in the field-of-view. The $\eta$ factor can thus take lower values than 0.5 for certain ice cloud particles (Chepfer et al. 1999). In addition, for particles smaller than the wavelength, photons are more likely to leave the field-of-view and the $\eta$ factor can take values larger than 0.5. Figure $1 \mathrm{~d}$ shows that the $\eta$ factor estimated from ICESat data can range between 0.2 and 1. Figure 7 shows the sensitivity of the mean results to multiple scattering representation using three different values of $\eta(0.7,0.5$, and 0.3$)$. The $\eta$ value influences the simulated profiles, but the discrepancies underlined in previous sections remain between 6 and $10 \mathrm{~km}$ (the simu- 
(a)
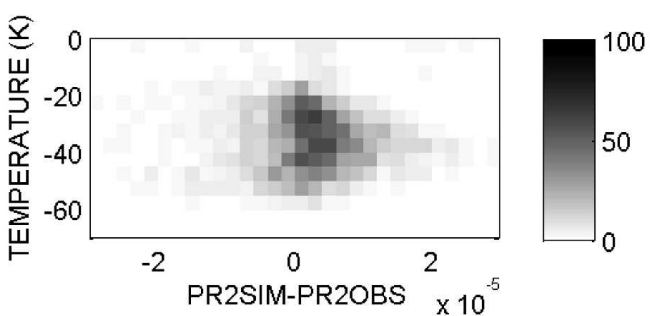

(b)
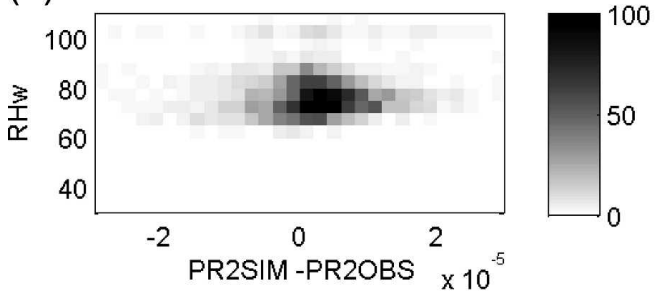

(c)

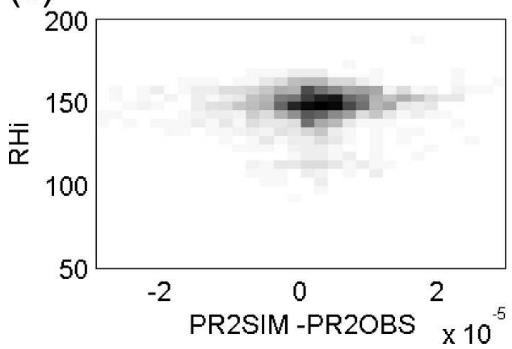

(d)

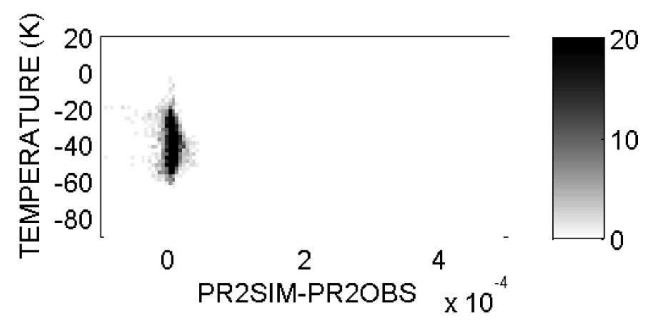

(e)

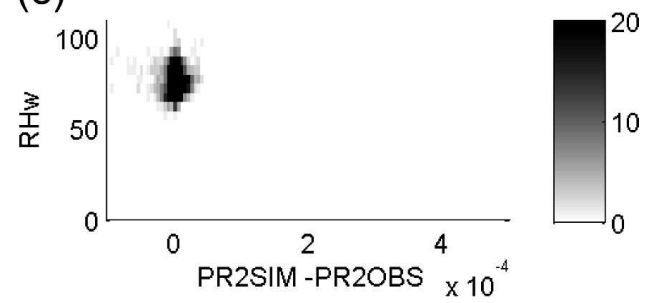

(f)

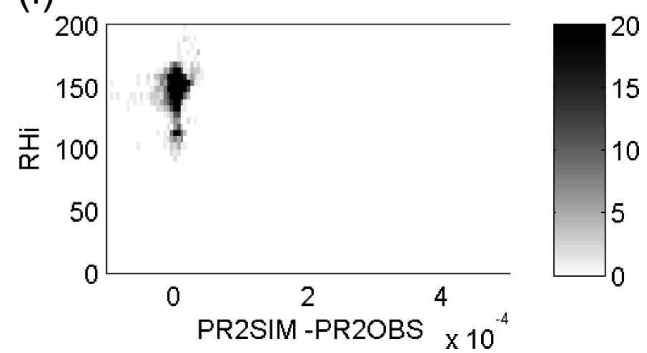

FIG. 6. Bias ( $x$ axis) between lidar observed and simulated signals when both consistently detect a cloud (Data_obs_3 and Data_sim_3), as a function of ( $y$ axis) T, RHw, and RHi. In (a)-(c) the simulated signal contains ice particles only. In (d)-(f) the simulated signal contains all thermodynamical phases: ice, snow, and liquid (different scale).

lated signal is larger than the observed one), and we conclude that the treatment of multiple scattering phenomena in ActSim is likely not the unique cause of the discrepancy between simulated and observed profiles.

\section{b. Errors in the humidity and temperature fields}

Errors in the humidity and temperature fields used to initialize and force the model could lead to discrepancies between model (MM5) and observations (NCEP). The uncertainty of those fields may play a role, but in the absence of a systematic bias the high number of points used here allows for the consideration of numerous variations in atmospheric situations leading to an insignificant difference between the model and observations on average, precluding a possible uncertainty to be the cause of the differences. Numerical bias are induced by the analysis, which does not always perfectly predict humidity and temperature measured in the upper troposphere by radio soundings or by radiances, leading typically to an overestimation of $+50 \%$ in $\mathrm{RHw}$ at $300 \mathrm{hPa}$ over Europe in autumn, by comparison with radio sounding. In addition, the radio sounding measurements themselves are likely to be biased in the upper troposphere because of the sensors' difficulties at very low temperatures. The bias in the uppertropospheric humidity measured by radiosondes has not been estimated statistically but several field experiments (Gierens et al. 2000; Ovarlez et al. 2002; Wang et al. 2003; Sapucci et al. 2005) compared airborne humidity measurements with radio sounding observations and have shown that the upper tropospheric humidity measured routinely by radio sounding is underestimated by a factor of 2. Because the numerical NCEP bias and the radio-sounding bias in the upper $\mathrm{RH}$ are of opposite sign, it is difficult to get a definitive bias estimate, but the order of magnitude of the radio-sounding bias is larger than the numeric one, suggesting that an uppertropospheric dry bias is likely to occur. Given that the 


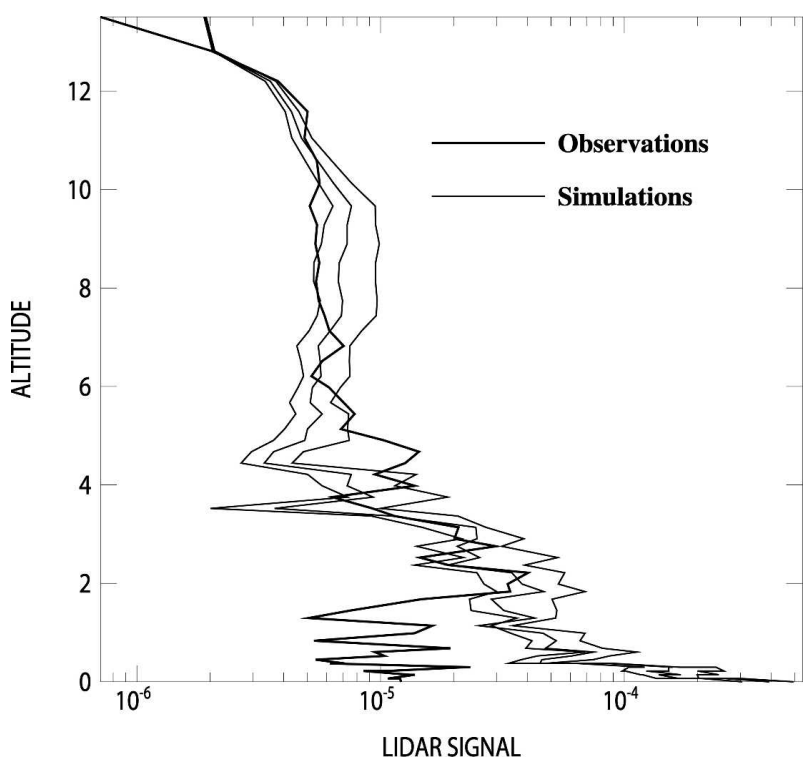

FIG. 7. Sensitivity of the simulated mean signal to the multiple scattering correction. The three simulated curves correspond to the following multiple scattering factors: $\eta=0.3$ associated with the larger values of lidar signal, 0.5 (middle), and 0.7 (smaller signal).

cloud occurrence in the model is simply specified as a function of the water vapor humidity in the atmosphere, a dry bias in RH at very low temperatures could explain the insufficient cloud amount produced by the model. On the other hand, the overestimation of the cloud occurrence simulated around $130 \%-140 \%$ RHi and cold temperatures $\left(-20^{\circ}\right.$ to $\left.-60^{\circ} \mathrm{C}\right)$ may be partly due to the supersaturation phenomena (water vapor that do not condensate even if $\mathrm{RHi}>100 \%$ ) in the upper troposphere that are regularly observed (Gierens et al. 2000; Ovarlez et al. 2002) but do no exist in the model where the water vapor condense as soon as RHi $>100 \%$. It could also be produced by clouds that are too persistent over time.

\section{c. The model cloud scheme}

The model cloud scheme is another possible cause that explains the differences between the model and observations. The simulated lidar profile is mostly overestimated in ice clouds and in boundary layer liquid clouds as soon as the cloud is created (assuming the multiple scattering factor is not larger than 0.7 as shown in Fig. 7). The discrepancy could be caused by several things, among which are wrong particle sizes, concentration, or water amount, as these parameters directly influence the lidar profile (see the appendix). Other parameters, such as the fall velocity of ice crystals could also induce errors: for example, if the simulated fall velocity is too small [as suggested in Chiriaco et al.
(2006)], the residence time of ice in the atmosphere is too long, and the cloud could become optically too thick. As a first rough attempt to understand the reason why the simulated lidar profile is overestimated, the exponential term of the lidar equation can be neglected [Eq. (A1)] as the exponent term corresponds to the optical depth that is, on average, lower than 0.5 in the upper atmosphere and lower than 2 when including the entire vertical column (Fig. 5b). Then the lidar signal is reduced to the backscatter coefficient $\beta$ [Eqs. (A1) and (A2)], which depends on the backscatter-to-extinction ratio $k$, the particle size $r$, and the particle concentration $n(r)$. So, errors in those three parameters may be the cause of the simulated lidar signal overestimation.

The particle sizes simulated by the model for the dataset under study are shown in Fig. 8: between 1 and $10 \mu \mathrm{m}$ for liquid clouds and 10 to $40 \mu \mathrm{m}$ for ice clouds. As those values seem realistic, the particle size may not be the cause of the simulated lidar signal overestimation.

The backscatter-to-extinction ratio $k$ in this range of particle size is quite constant (Fig. 9), so it may not be the cause of the simulated lidar signal overestimation.

If $r$ and $k$ are realistic, the overestimation of the simulated lidar signal is likely to be due to an overestimation of the particle number [Eq. (A3)].

In the model, the particle sizes $\left(r_{\text {ice }}\right)$ and $\left(r_{\text {liq }}\right)$ are diagnosed from $n_{\text {ice }}(r)$ and $n_{\text {liq }}$, the latter being constant. Here, $r_{\text {ice }}^{3}$ is proportional to IWC $/ n_{\text {ice }}(r)$ and $r_{\text {liq }}^{3}$ is proportional to $\mathrm{LWC} / n_{\mathrm{liq}}(r)$. So the realistic values of particles size may be due to a simultaneous overestimation of both water contents and particle concentrations. Moreover, $\beta_{\text {ice }}$ is proportional to $\operatorname{IWC}^{2 / 3} n_{\text {ice }}^{1 / 3}$, meaning that an error in the content will have more impact on the measurement than error in the particle concentration for both ice and liquid water clouds.

Three possible sources of error have been discussed in this paper. Nevertheless other ones such as supercooled liquid water clouds or pockets of supercooled liquid water in ice clouds (Hogan et al. 2004) that are frequently observed in midlatitudes, but are not reproduced in the models, cannot be excluded asplaying a role in the disagreement between observations and simulations as they would have a direct significant impact on the lidar signal.

\section{Conclusions}

An intensive comparison of the performance of MM5 to simulate clouds over Europe was presented, by original means of statistical comparisons between lidar in 

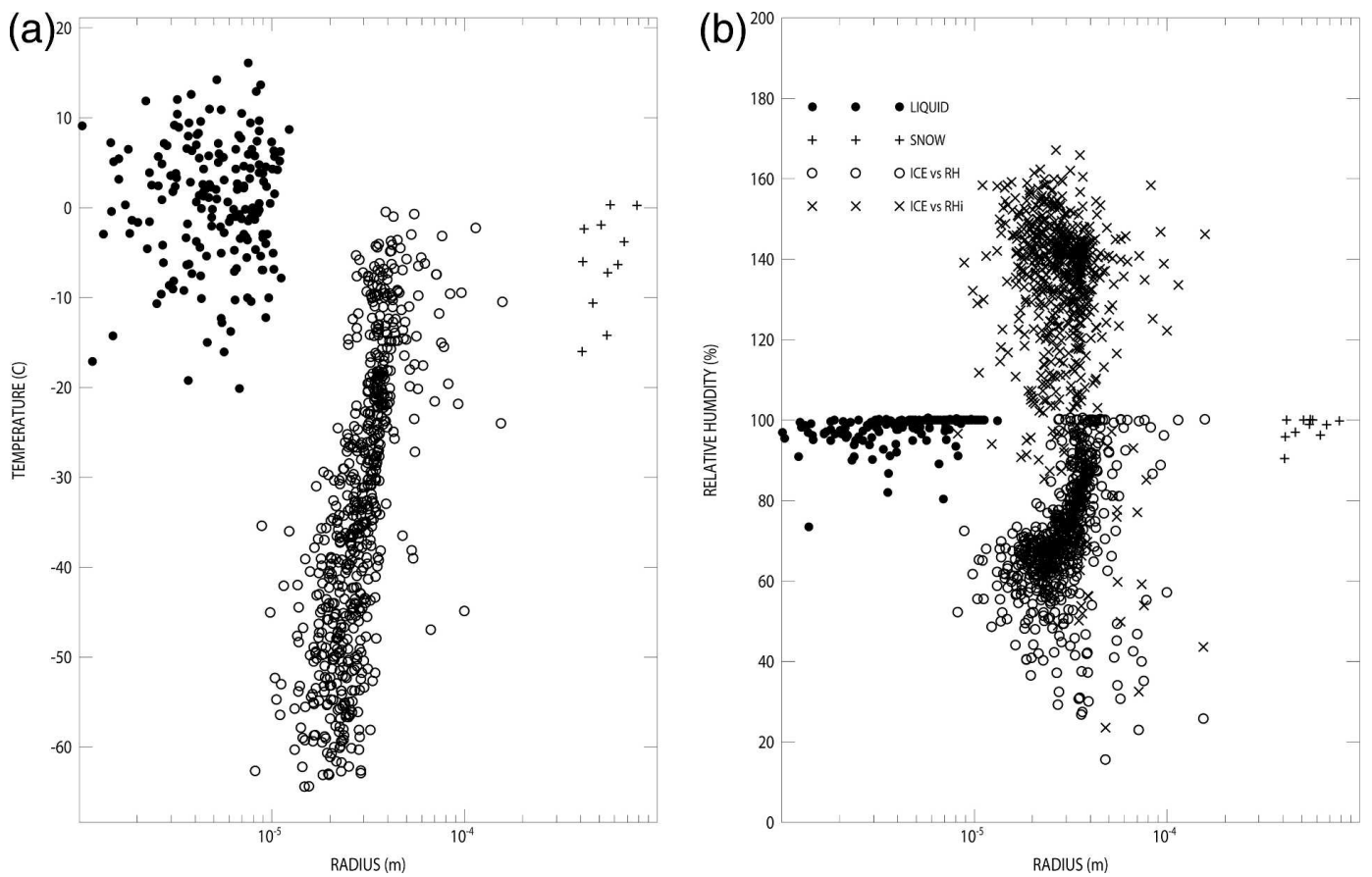

FIG. 8. Particle sizes simulated using the 77 ICESat orbits (Data_sim_3). Particle size as a function of (a) temperature and (b) humidity. Particles with sizes less than $1 \mu \mathrm{m}$ are neglected.

space observations and simulations during one month in the autumn of 2003. Lidar profiles were diagnosed from model fields, allowing direct comparisons between observations and simulations, without inversion of the observed lidar signal. This approach is different from and complementary to the one used by Mace et al. (1998), Miller et al. (1999), Miller and Stephens (2001), and Palm et al. (2005) who used radar and lidars to evaluate ECMWF cloud prediction.

The main limitation of such model evaluation exercises using lidar data is that the portion of the atmosphere sounded by the lidar corresponds only to clouds with optical depths typically lower than 2.5 , precluding the study of optically thick clouds. MM5 overestimates the lidar signals, on average, in the upper troposphere $(z>6 \mathrm{~km})$ and underestimates it at lower altitudes. A simple cloud detection was applied identically to both observed and simulated lidar signals in order to identify the part of the error due to false cloud occurrence and to incorrectly parameterized cloud properties in the model. The discrepancy in cloud occurrence is a result of disagreement between observations and simulations. Simulated high cloud with large optical depth are too frequently produced by the model $(40 \%-50 \%$ overestimation), while the occurrence of optically thin clouds is correct or too rare $(0 \%-20 \%$ underestimation). Lowlevel cloud occurrence seems more correct, although the masking effect due to high clouds and their simu- lation-observation differences does not allow a firm conclusion.

Most of these clouds are not reproduced at exactly the same time and space as they are observed. The upper clouds amount missed by the model occur predominantly when the temperature is very low $\left(-50^{\circ}\right.$ to $-60^{\circ} \mathrm{C}$ ), which could be because of a dry bias in NCEP humidity data in the very upper troposphere that are used to initialize MM5. The upper-troposphere humid-

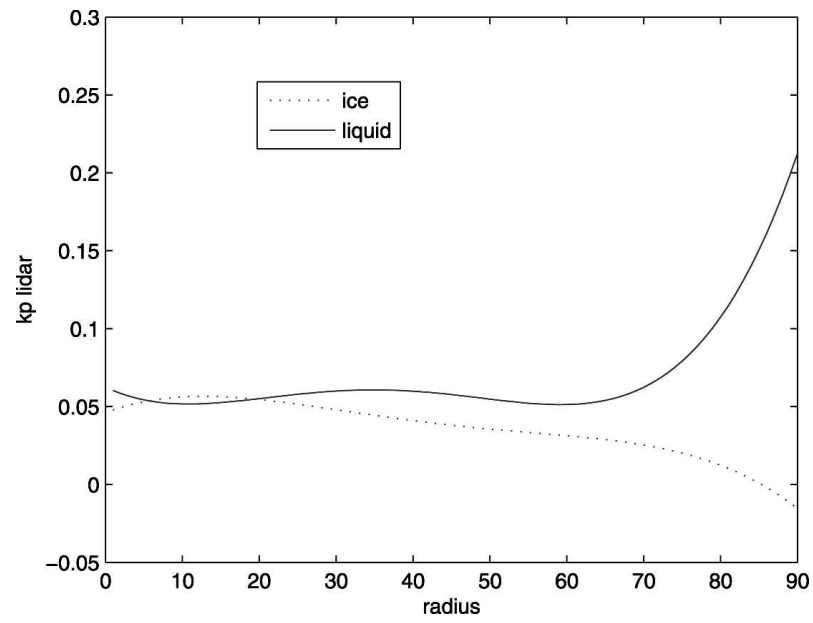

FIG. 9. Lidar backscatter-to-extinction ratio as a function of the particle radius. 
ity is usually underestimated by radio sounding. This could explain the underestimation of the frequency of thinner tropopause ice clouds. The ice cloud amount with the temperature ranging between $-20^{\circ}$ and $-50^{\circ} \mathrm{C}$ is overestimated most of the time when RHi $>100 \%$. The supersaturations $(\mathrm{RHi}>100 \%$ without condensation) that have been observed in situ in ice clouds (Gierens et al. 2000; Ovarlez et al. 2002) and that are not reproduced in models (that condensate as soon as RHi $>100 \%$ ) may explain part of this overestimation. Another possibility is that when the cloud is created in the model, it is optically too thick and/or too persistent in time. The low-level cloud amount is slightly underestimated between $60 \%$ and $100 \%$ of $\mathrm{RHw}$ at higher temperatures. That could be an artifact due to the simple cloud detection used here, which does not allow differentiating between aerosols and clouds. That could also result from the fact that MM5 does not consider fractionary clouds, hence inhibiting subgrid-scale cumulus clouds to appear at lower RH than $100 \%$ over the whole model cell.

When high clouds occur simultaneously in both observations and simulations, the simulated lidar signal is systematically higher than the observed one. It is the same in low-level water clouds, but ICESat does not provide a representative figure of those optically thick clouds. There is no evident link between this overestimation and the atmospheric thermodynamical conditions. Because the variability of the size of the particles composing these clouds is reasonable, on average, in the model in both ice and liquid water cloud, this indicates that as soon as the model creates a cloud, the particle concentration and the water content (liquid or ice) are simultaneously too large (assuming the cloud is not composed of very small particles so that the multiple scattering factor is not higher than 0.7). The liquid particle number is considered as constant in the model whereas the ice particle concentration is parameterized.

Finally, this study shows that active spaceborne remote sensing observations can be used to evaluate the ability of meteorological mesoscale models to simulate clouds, and particularly high clouds in a systematic manner, using a simple and robust model-toobservation approach. The advance over comparisons done with passive cloud observation is the direct information on the cloud height. Our analysis offers some possible explanations for these discrepancies, but a full understanding requires complementary datasets to the lidar because of the masking of low clouds by high clouds. More over the results obtained here are based on a limited dataset (one month in the autumn), which is not neutral with respect to the cloud type and model performances (e.g., one may expect the limitation of convection scheme to be less crucial here). Future observations collected simultaneously with lidar and radar in space (Stephens et al. 2002) should allow extending this kind of study to optically thicker clouds and get more valuable results for the low-level water clouds.

Acknowledgments. The authors acknowledge D. Dudhia for feedbacks on MM5 model. MM5 simulation data handling was performed by Yann Wanherdrick.

\section{APPENDIX}

\section{Lidar Equation}

The lidar equation can be written as

$$
\begin{aligned}
S_{\lambda}(z) z^{2}= & K_{\lambda}\left[\beta_{\text {sca,part }, \lambda}(z)\right. \\
& \left.+\beta_{\text {sca,mol }, \lambda}(z)\right] e^{-2 \int\left[\eta \alpha_{\text {sca, }, p a r t, \lambda}+\alpha_{\text {sca,mol }, \lambda}(z)\right] d z},
\end{aligned}
$$

where $S_{\lambda}(z)$ is the lidar signal $\left(\mathrm{W} \mathrm{m}^{-2} \mathrm{sr}^{-1}\right), K_{\lambda}$ is the calibration constant, $\beta_{\text {sca,part }, \lambda}$ and $\beta_{\text {sca,mol }, \lambda}$ are the lidar backscatter coefficient $\left(\mathrm{m}^{-1} \mathrm{sr}^{-1}\right)$ for particles and molecules, $\eta$ is the multiple scattering coefficient, and $\alpha$ is the attenuation coefficient $\left(\mathrm{m}^{-1}\right)$. Here,

$$
\beta_{\text {sca,part }, \lambda}(z)=k_{\text {part }}(z) \alpha_{\text {sca,part }, \lambda}(z),
$$

where $k$ is the backscatter-to-extinction $\left(\mathrm{sr}^{-1}\right)$ ratio proportional to the particle scattering phase function in backscattering. Here,

$$
\alpha_{\text {sca,part }, \lambda}(z)=\int \pi r^{2} Q_{\lambda}(r) n(r, z) d r,
$$

where $\alpha_{\text {sca,part }, \lambda}$ is the attenuation coefficient due to the scattering processes, $r$ is the radius (m), $Q_{\lambda}(r)$ is the scattering efficiency, and $n(r, z)$ is the size distribution $\left(\mathrm{m}^{-3}\right)$.

\section{REFERENCES}

Ackerman, T., and G. Stokes, 2003: The Atmospheric Radiation Measurements program. Phys. Today, 56, 38-45.

Baum, B. A., P. F. Soulen, K. I. Strabala, M. D. King, S. A. Ackerman, W. P. Menzel, and P. Yang, 2000: Remote sensing of cloud properties using MODIS airborne simulator imagery during SUCCESS. II. Cloud thermodynamic phase. J. Geophys. Res., 105, 11 781-11 792.

Beljaars, A. C. M., 1995: The parameterization of surface fluxes in large-scale models under free convection. Quart. J. Roy. Meteor. Soc., 121, 255-270.

Bissonnette, L. R., G. Roy, and F. Fabry, 2001: Range-height scans of lidar depolarization for characterizing properties and phase of clouds and precipitation. J. Atmos. Oceanic Technol., 18, 1429-1446.

Boucher, O., H. Le Treut, and M. B. Baker, 1995: Precipitation and radiation modeling in a general circulation model: Introduction of cloud microphysical processes. J. Geophys. Res., 100, $16395-16414$. 
Campbell, J. R., D. L. Hlavka, E. J. Welton, C. J. Flynn, D. D. Turner, J. D. Spinhirne, V.S. Scott III, and I. H. Hwang, 2002: Full-time, eye-safe cloud and aerosol lidar observation at atmospheric radiation measurement program sites: Instrument and data processing. J. Atmos. Oceanic Technol., 19, $431-442$.

Chepfer, H., J. Pelon, G. Brogniez, C. Flamant, V. Trouillet, and P. H. Flamant, 1999: Impact of cirrus cloud ice crystal shape and size on multiple scattering effects: application to spaceborne and airborne backscatter lidar measurements during LITE mission and E LITE campaign. Geophys. Res. Lett., 26, 2203-2206.

— , P. Goloub, J. Riedi, J. F. De Haan, J. W. Hovenier, and P. H. Flamant, 2001: Ice crystal shapes in cirrus clouds derived from POLDER/ADEOS-1. J. Geophys. Res., 106, 7955-7966.

Chiriaco, M., R. Vautard, H. Chepfer, M. Haeffelin, J. Dudhia, Y. Wanherdrick, Y. Morille, and A. Protat, 2006: The ability of MM5 to simulate ice clouds: Systematic comparison between simulated and measured fluxes and lidar/radar profiles at the SIRTA Atmospheric Observatory. Mon. Wea. Rev., 134, 897 918

Del Genio, A. D., M.-S. Yao, W. Kovari, and K. K.-W. Lo, 1996: A prognostic cloud water parameterization for global climate models. J. Climate, 9, 270-304.

Deschamps, P. Y., F. M. Bréon, M. Leroy, A. Podaire, A. Brickaud, J. C. Buriez, and G. Sèze, 1994: The POLDER mission: Instrument characteristics and scientific objectives. IEEE Trans. Geosci. Remote Sens., 32, 598-615.

Dudhia, J., 1989: Numerical study of convection observed during the Winter Monsoon Experiment using a mesoscale twodimensional model. J. Atmos. Sci., 46, 3077-3107.

- 1993: A nonhydrostatic version of the Penn State-NCAR mesoscale model: Validation tests and simulation of an Atlantic cyclone and cold front. Mon. Wea. Rev., 121, 14931513.

Gierens, K., U. Schumann, M. Helten, H. Smit, and P.-H. Wang, 2000: Ice-supersaturated regions and subvisible cirrus in the northern midlatitude upper troposphere. J. Geophys. Res., 105, $22743-22754$.

Goloub, P., M. Herman, H. Chepfer, J. Riedi, G. Brogniez, P. Couvert, and G. Séze, 2000: Cloud thermodynamical phase classification from the POLDER spaceborne instrument. $J$. Geophys. Res., 105, 14 747-14 760.

Grell, G. A., 1993: Prognostic evaluation of assumptions used by cumulus parameterizations. Mon. Wea. Rev., 121, 764-787.

Guichard, F., D. B. Parsons, J. Dudhia, and J. Bresch, 2003: Evaluating mesoscale model predictions of clouds and radiation with SGP ARM data over a seasonal timescale. Mon. Wea. Rev., 131, 926-944.

Hack, J. J., B. A. Boville, B. P. Briegleb, J. T. Kiehl, P. J. Rasch, and D. L. Williamson, 1993: Description of the NCAR Community Climate Model (CCM2). NCAR Tech. Note NCAR/ TN-382+STR, National Center for Atmospheric Research, Boulder, CO, 108 pp.

Haeffelin, M., and Coauthors, 2005: SIRTA, a French atmospheric observatory for clouds, aerosols and water vapor. Ann. Geophys., 23, 253-275.

Hart, W. D., J. D. Spinhirne, S. P. Palm, and D. L. Hlavka, 2005: Height distribution between cloud and aerosol layers from GLAS spaceborne lidar in the Indian Ocean region. Geophys. Res. Lett., 32, L22S06, doi:10.1029/2005GL023671.

Heckman, S. T., and W. R. Cotton, 1993: Mesoscale numerical simulation of cirrus clouds-FIRE case study and sensitivity analysis. Mon. Wea. Rev., 121, 2264-2284.

Heymsfield, A. J., and C. M. R. Platt, 1984: A parameterization of the particle size spectrum of ice clouds in terms of the ambient temperature and the ice water content. J. Atmos. Sci., 41, 846-855.

- , and L. J. Donner, 1990: A scheme for parameterizing icecloud water content in general circulation models. J. Atmos. Sci., 47, 1865-1877.

Hlavka, D. L., S. P. Palm, W. D. Hart, J. D. Spinhirne, M. J. McGill, and E. J. Welton, 2005: Aerosols and cloud optical depth from GLAS: Results and verification for an October 2003 California fire smoke case. Geophys. Res. Lett., 32, L22S07, doi:10.109/2005GL023413.

Hogan, R. J., M. D. Behera, E. J. O'Connor, and A. Illingworth, 2004: Estimate of the global distribution of stratiform supercooled liquid water clouds using the LITE lidar. Geophys. Res. Lett., 31, L05106, doi:10.1029/2003GL018977.

Jenson, E., D. Starr, and O. B. Toon, 2004: Mission investigates tropical cirrus clouds. Eos, Trans. Amer. Geophys. Union, 85, 45, doi:10.1029/2004EO050002.

Jin, Y., W. B. Rossow, and D. P. Wylie, 1996: Comparison of the climatologies of high-level clouds from HIRS and ISCCP. $J$. Climate, 9, 2850-2879.

King, M. D., and Coauthors, 1996: Airborne scanning spectrometer for remote sensing of cloud, aerosol, water vapor, and surface properties. J. Atmos. Oceanic Technol., 13, 777-794.

- , and Coauthors, 2003: Cloud and aerosol properties, precipitable water, and profiles of temperature and humidity from MODIS. IEEE Trans. Geosci. Remote Sens., 41, 442-458.

Levkov, L., B. Rockel, H. Kapitza, and E. Raschke, 1992: 3D mesoscale numerical studies of cirrus and stratus clouds by their time and space evolution. Beitr. Phys. Freien Atmos., 65, $35-57$.

, H. Schiller, and L. Kornblueh, 1998: 3-D simulation of clouds with subgrid fluctuations of temperature and humidity. Atmos. Res., 47-48, 327-341.

Liou, K.-N., 1986: Influence of cirrus clouds on weather and climate processes: A global perspective. Mon. Wea. Rev., 114, 1167-1199.

—, 2002: An Introduction to Atmospheric Radiation. International Geophysics Series, Vol. 84, Academic Press, 175 pp.

Liu, Y., F. Chen, T. Warner, and S. Swerdlin, 2004: Improvements to surface flux computations in the MRF PBL scheme, and refinements to urban processes in the NOAH land-surface model with the NCAR/ATEC real-time FDDA and forecast system. Proc. First Joint WRF/MM5 User's Workshop, Boulder, CO, NCAR.

Mace, G. G., C. Jakob, and K. P. Moran, 1998: Validation of hydrometeor occurrence predicted by the ECMWF model using millimeter wave radar data. Geophys. Res. Lett., 25, 16451648 .

Macke, A., J. Mueller, and E. Raschke, 1996: Single scattering properties of atmospheric ice crystals. J. Atmos. Sci., 53, $2813-2825$

McFarquhar, G. M., and A. J. Heymsfield, 1996: Microphysical characteristics of three anvils sampled during the Central Equatorial Pacific Experiment. J. Atmos. Sci., 53, 2401-2423.

Miller, S. D., and G. L. Stephens, 2001: CloudSat instrument requirements as determined from ECMWF forecasts of global cloudiness. J. Geophys. Res., 106, 17 713-17 734.

,-- , and A. C. M. Beljaars, 1999: A validation survey of the 
ECMWF prognostic cloud scheme using LITE. Geophys. Res. Lett., 26, 1417-1420.

Minnis, P., D. P. Garber, D. F. Young, R. F. Arduini, and Y. Takano, 1998: Parameterizations of reflectance and effective emittance for satellite remote sensing of cloud properties. $J$. Atmos. Sci., 55, 3313-3339.

Nicolas, F., L. R. Bissonnette, and P. H. Flamant, 1997: Lidar effective multiple-scattering coefficients in cirrus clouds. Appl. Opt., 36, 3458-3468.

Noel, V., H. Chepfer, M. Haeffelin, and Y. Morille, 2006: Classification of ice crystal shapes in midlatitude ice clouds from three years of lidar observations over the SIRTA observatory. J. Atmos. Sci., 63, 2978-2991.

Ovarlez, J., J.-F. Gayet, K. Gierens, J. Ström, H. Ovarlez, F. Auriol, R. Busen, and U. Schumann, 2002: Water vapour measurements inside cirrus clouds in Northern and Southern hemispheres during INCA. Geophys. Res. Lett., 29, 1813, doi:10.1029/2001GL014440.

Palm, S. P., A. Benedetti, and J. Spinhirne, 2005: Validation of ECMWF global forecast model parameters using GLAS atmospheric channel measurements. Geophys. Res. Lett., 32, L22S09, doi:10.1029/2005GL023535.

Platnick, S., M. D. King, S. A. Ackerman, W. P. Menzel, B. A. Baum, J. C. Riedi, and R. A. Frey, 2003: The MODIS cloud products: Algorithms and examples from Terra. IEEE Trans. Geosci. Remote Sens., 41, 459-473.

Platt, C. M. R., 1973: Lidar and radiometric observations of cirrus clouds. J. Atmos. Sci., 30, 1191-1204.

—, N. L. Abshire, and G. T. McNice, 1978: Some microphysical properties of an ice cloud from lidar observation of horizontally oriented crystals. J. Appl. Meteor., 17, 1220-1224.

Randall, D., B. Albrecht, S. Cox, D. Johnson, P. Minnis, W. Rossow, and D. Starr, 1996: On FIRE at ten. Advances in Geophysics, Vol. 38, Academic Press, 137-177.

Raschke, E., P. Flamant, Y. Fouquart, P. Hignett, H. Isaka, P. R. Jonas, H. Sundquist, and P. Wendling, 1998: Cloud radiation studies during the European Cloud Radiation Experiment (EUCREX). Surv. Geophys., 19, 89-138.

Reisner, J., R. M. Rasmussen, and R. T. Bruintjes, 1998: Explicit forecasting of supercooled liquid water in winter storms using the MM5 mesoscale model. Quart. J. Roy. Meteor. Soc., 124, 1071-1107.

Rossow, W. B., and R. A. Schiffer, 1999: Advances in understanding clouds from ISCCP. Bull. Amer. Meteor. Soc., 80, 22612287.

Sapucci, L. F., L. A. T. Machado, R. B. da Silveira, G. Fisch, and J. F. G. Monico, 2005: Analysis of relative humidity sensors at the WMO Radiosonde Intercomparison Experiment in Brazil. J. Atmos. Oceanic Technol., 22, 664-678.

Sassen, K., 1991: The polarization lidar technique for cloud re- search: A review and current assessment. Bull. Amer. Meteor. Soc., 72, 1848-1866.

_, and S. Benson, 2001: A midlatitude cirrus cloud climatology from the facility for atmospheric remote sensing. Part II: Microphysical properties derived from lidar depolarization. $J$. Atmos. Sci., 58, 2103-2112.

Spinhirne, J. D., S. P. Palm, W. D. Hart, D. L. Hlavka, and E. J. Welton, 2005: Cloud and aerosol measurements from GLAS: Overview and initial results. Geophys. Res. Lett., 32, L22S03, doi:10.1029/2005GL023507.

Stephens, G. L., S.-C. Tsay, P. W. Stackhouse Jr., and P. J. Flatau, 1990: The relevance of the microphysical and radiative properties of cirrus clouds to the climate and climatic feedback. $J$. Atmos. Sci., 47, 1742-1753.

— A new dimension of space-based observations of clouds and precipitation. Bull. Amer. Meteor. Soc., 83, 1771-1790.

Takano, Y., and K.-N. Liou, 1989: Solar radiative transfer in cirrus clouds. Part I: Single-scattering and optical properties of hexagonal ice crystals. J. Atmos. Sci., 46, 3-19.

Toon, O. B., and R. C. Miake-Lye, 1998: Subsonic Aircraft: Contrail and Cloud Effects Special Study (SUCCESS). Geophys. Res. Lett., 25, 1109-1112.

Troën, I., and L. Mahrt, 1986: A simple model of the atmospheric boundary. Sensitivity to surface evaporation. Bound.-Layer Meteor., 37, 129-148.

Wang, J., D. J. Carlson, D. B. Parsons, T. F. Hock, D. Lauritsen, H. L. Cole, K. Beierle, and E. Chamberlain, 2003: Performance of operational radiosonde humidity sensors in direct comparison with chilled mirror dew-point hygrometer and its climate implication. Geophys. Res. Lett., 30, 1860, doi:10.1029/2003GL016985.

Wetzel, M. A., and G. T. Bates, 1995: Comparison of simulated cloud cover with satellite observations over the western United States. J. Climate, 8, 296-314.

Wylie, D. P., and P.-H. Wang, 1999: Comparison of SAGE-II and HIRS co-located cloud height measurements. Geophys. Res. Lett., 26, 3373-3376.

_ P. Piironen, W. Wolf, and E. Eloranta, 1995: Understanding satellite cirrus cloud climatologies with calibrated lidar optical depths. J. Atmos. Sci., 52, 4327-4343.

Yakohata, T., S. Eimori, T. Nozawa, Y. Tsushima, T. Ogura, and M. Kimoto, 2005: Climate response to volcanic forcing: Validation of climate sensitivity of coupled atmosphere-ocean general circulation model. Geophys. Res. Lett., 32, L21710, doi:10.1029/2005GL023542.

Yang, P., and K.-N. Liou, 1998: Single-scattering properties of complex ice crystals in terrestrial atmosphere. Contrib. Atmos. Phys., 71, 223-248. 